\title{
INDICADORES COMPARADOS DA PRODUÇÃO AGRÍCOLA DA REGIÃO METROPOLITANA DE SOROCABA EMPREGO, RENDA E CAPITAL HUMANO
}

Francisco Carlos Ribeiro' Flaviano Agostinho de Lima $^{2}$ Vidal Dias da Mota Júnior ${ }^{3}$ Roger Augusto de Camargo ${ }^{4}$

Célio Olderigi de Conti ${ }^{5}$ Luiz Carlos Rosa ${ }^{6}$

\section{RESUMO}

A Região Metropolitana de Sorocaba é a segunda região metropolitana com maior participação agrícola do estado de São Paulo. Até a criação da Região Metropolitana de Ribeirão preto ser criada, figurava como a mais agrícola. Destaca-se também por ter uma Olericultura diversificada e responde, ainda, por $20 \%$ do volume de produção e $22 \%$ do valor bruto da produção do Estado de São Paulo. Mas quando, cruzamos números de estabelecimentos e emprego formal, encontramos manifestações de comportamento curiosas, que demandam mais pesquisas. A Região Metropolitana de Sorocaba tem instituiçôes de ensino superior e pessoal docente capacitado para desenvolver pesquisas para inúmeras perguntas que se apresentam. Um campo enorme de pesquisas locais se abre. Palavras-chave: Região metropolitana; Olericultura; Região metropolitana de Sorocaba; Pesquisas; Emprego e renda.

1 Faculdade de Tecnologia de Sorocaba José Crespo Gonzales (Fatec Sorocaba) - Centro Paula Souza.

2 Faculdade de Tecnologia Prof. Wilson Roberto Ribeiro de Camargo (Fatec Tatuí) -Centro Paula Souza.

3 Universidade de Sorocaba - Uniso.

4 (MAPA) Economista - Consultor do Ministério da Agricultura Pecuária e Abastecimento.

5 Correspondência com os autores em francisco.ribeiro@fatec.sp.gov.br.

6 Faculdade de Tecnologia de Sorocaba (FATEC) - Centro Paula Souza. 
-• Economia Brasileira em Debate

\section{INTRODUÇÃO}

A Região Metropolitana de Sorocaba (RMS) é a segunda Região Metropolitana com maior participação agrícola no estado de São Paulo. É importante compreender a sua dimensão como potencial para a atividade econômica, bem como para a geração de Empregos. Em 2016, segundo dados do Caged, o setor empregava 23.670 pessoas de um total de 508.079 empregos, perfazendo uma participação de $4,66 \%$ do total de empregos.

Dessa maneira, abre-se um cenário importante para pesquisas sobre a economia agrícola e a geração de empregos, inclusive como potencial à Agroindústria. Considerando o número de desempregados no Brasil, 12,3 milhôes de desempregados, só no estado de São Paulo tem-se 1.883 mil deles. Na Região Metropolitana de Sorocaba ainda não há dados desagregados para uma estimativa mais segura.

Considerando, entretanto, a importância da Agricultura para a Região Metropolitana em questão, abre-se, via agricultura, agronegócios ou mesmo setor de alimentação, possibilidades importantes para emprego. Tais possibilidades precisam ser medidas, ponderadas, analisadas e transformadas em políticas públicas apropriadas. Necessitamos sair do intuitivo, para mergulharmos no universo empírico e a partir daí tirar as devidas conclusões e políticas.

\section{INDICADORES DO SETOR AGROPECUÁRIO: DO BRASIL À REGIÃO METROPOLITANA DE SOROCABA (RMS)}

\subsection{A Participação da Agropecuária no PIB, no número de estabelecimentos e no volume de emprego no Brasil.}

Conforme podemos observar nas Contas Nacionais, a participação do setor agropecuário no Produto Interno Bruto recuou um pouco entre 2013 e 2015 conforme apresentado na Tabela 1.

Tabela 1 Participação do Setor Agropecuário no PIB.

\begin{tabular}{|c|c|}
\hline Ano & Participação (em\%) \\
\hline 2013 & 4,52 \\
\hline 2014 & 4,47 \\
\hline 2015 & 4,46 \\
\hline
\end{tabular}

Fonte: Elaboração dos autores com dados das Contas Nacionais - IBGE. 
A participação do setor agropecuário no número total de estabelecimentos é da ordem de 6,38\%, ou seja, temos 522.866 estabelecimentos, num total de 8.197.918 estabelecimentos legalmente constituídos no Brasil. (Caged, 2016). Na geração de empregos formais, a participação do setor agropecuário é de 3,92\%, ou seja, representando 1.555 .522 empregos formais num universo de 39.693 .050 o que é bastante significativo.

Assim, na Tabela 2, apresentamos uma síntese desses indicadores com o objetivo de realizar as devidas comparaçôes com a RMS.

Tabela 2 Participação do setor Agropecuário.

\begin{tabular}{|c|c|c|}
\hline No PIB (2013) & $\begin{array}{c}\text { No total de Estabelecimentos } \\
(2016)\end{array}$ & $\begin{array}{c}\text { No total de empregos } \\
(2016)\end{array}$ \\
\hline $4,52 \%^{7}$ & $6,38 \%$ & $3,92 \%$ \\
\hline
\end{tabular}

Fonte: IBGE - Contas Nacionais - Caged. Elaboração dos autores.

\subsection{Setor Agropecuário no Estado de São Paulo}

Quanto ao Estado de São Paulo, observa-se uma configuração distinta da nacional, porém, acompanhando o recuo nacional conforme é possível verificar na Tabela 3 a participação do setor Agropecuário no Valor Adicionado do Estado.

Tabela 3 Participação do setor Agropecuário no Estado de São Paulo.

\begin{tabular}{|c|c|}
\hline Períodos & Participação da Agropecuária no Total do Valor Adicionado (Em\%) \\
\hline 2010 & 2,11 \\
\hline 2011 & 1,98 \\
\hline 2012 & 1,86 \\
\hline 2013 & 1,87 \\
\hline
\end{tabular}

Fonte: Seade. Elaboração dos autores.

Conforme é possível depreender na Tabela 4, na qual consta o número de estabelecimentos e empregos, o setor representa $7,73 \%$ das unidades produtivas do

7 Os dados, para valores adicionados, no Estado e municípios, limitam-se até 2013. O volume total de empregos e perfil municipal do Caged é de janeiro de 2016. Assim, considerando datas diferentes de base de dados, as análises estão sujeitas a pequenas imperfeições. 
-• Economia Brasileira em Debate

Estado (estabelecimentos), ou seja, 188.941 de um total de 2.445 .674 e 2,84\% dos empregos formais, ou seja, 350.046 de um total de 12.311.299 empregos formais do Estado de São Paulo.

Tabela 4 Setor Agropecuário no Estado de São Paulo.

\begin{tabular}{|c|c|c|}
\hline No VA (2013) & $\begin{array}{c}\text { No total de Estabelecimentos } \\
(2016)\end{array}$ & $\begin{array}{c}\text { No total de empregos } \\
(2016)\end{array}$ \\
\hline $1,87 \%$ & $7,73 \%$ & $2,84 \%$ \\
\hline
\end{tabular}

Fonte: Seade - Caged. Elaboração dos autores.

Objetivando uma melhor análise comparativa, todos os dados anteriores foram sintetizados na Tabela 5.

Tabela 5 Setor Agropecuário Brasil-São Paulo.

\begin{tabular}{|c|c|c|l|}
\hline No PIB (2013) & $\begin{array}{c}\text { No total de Estabelecimentos } \\
(2016)\end{array}$ & $\begin{array}{c}\text { No total de empregos } \\
(2016)\end{array}$ & \multicolumn{1}{|c|}{ Origem } \\
\hline $4,52 \%$ & $6,38 \%$ & $3,92 \%$ & Brasil \\
\hline $1,87 \%^{8}$ & $7,73 \%$ & $2,84 \%$ & São Paulo \\
\hline
\end{tabular}

Fonte: Sead - Caged - Contas Nacionais - IBGE. Elaboração dos autores.

Contrapondo os indicadores da Tabela 5, podemos perceber que a participação do setor agropecuário na economia paulista é proporcionalmente menor do que no Brasil. Entendemos natural dada a grande concentração industrial e de serviços no estado. Também mais natural esperar que a participação no volume de empregos também se mostrasse menor, mas em termos proporcionais a diferença é menor. A participação do PIB do setor no Brasil é 141\% maior do que a de São Paulo", já essa relação quando analisada do ponto de vista da participação dos empregos formais é só 38\% menor que o Brasil e, quando olhamos a participação dos estabelecimentos a relação se inverte, ou seja, a participação no número de estabelecimentos no estado de São Paulo é 21,15\% maior do que no Brasil.

8 Valor Adicionado.

9 O dividendo foi o valor adicionado, então na verdade esse número é menor se computado os impostos. 
Tal comparativo sugere algumas indagações: a participação menor do setor agropecuário no PIB paulista, se deve a grande concentração industrial e de serviços no Estado? Naturalmente, assim o deduzimos. Mas somam-se aí outras indagações: Não obstante menor participação relativa do setor agropecuário no valor agregado, o estado de São Paulo tem maior participação relativa de estabelecimentos agrícolas do que no país e tem uma participação relativa apenas 38\% menor no volume de empregos. Será que isso se deve ao fato de que os estabelecimentos em São Paulo estão proporcionalmente mais formalizados que outros estados, e o que isso significa, já que no volume de empregos formais temos menor participação relativa? Será que é porque em São Paulo temos mais unidades de agricultura familiar e as culturas intensivas impactam sobre o volume de empregos formais, mas nem tanto sobre a quantidade de estabelecimentos? Há relação com uma estrutura produtiva formada por unidades menores em termos de área, dado o custo mais elevado do preço da terra? Essas especulaçóes que fazemos têm fundamento?

Respostas consistentes para essas indagações necessitariam de pesquisas que, nesse momento, não estão no escopo desse texto. $\mathrm{O}$ escopo aqui é apenas chamar a atenção para o universo de perguntas e potenciais pesquisas que o setor demanda para respondê-las. E as indagações apenas estão começando, pois, o nosso objeto não é o Estado, mas sim a Região Metropolitana de Sorocaba.

\subsection{O Setor Agropecuário na Região Metropolitana de Sorocaba}

A Região Metropolitana de Sorocaba é uma das "caçulas" entre as Regiōes Metropolitanas do Estado de São Paulo. Sua criação se deu em 8 de maio de 2014 através da Lei Complementar 1.241. Essa lei elencava o total de 26 municípios, a saber: Alambari, Alumínio, Araçariguama, Araçoiaba da Serra, Boituva, Capela do Alto, Cerquilho, Cesário Lange, Ibiúna, Iperó, Itu, Jumirim, Mairinque, Piedade, Pilar do Sul, Porto Feliz, Salto, Salto de Pirapora, São Miguel Arcanjo, São Roque, Sarapuí, Sorocaba, Tapiraí, Tatuí, Tietê e Votorantim. Através da Lei Complementar 1.289 de 29 de junho de 2016, Itapetininga passou a integrar a Região Metropolitana de Sorocaba, ficando a Região formada então por 27 municípios. $^{10}$

10 Todas as estatísticas a Respeito da Região Metropolitana de Sorocaba, aqui trabalhadas, o município de Itapetininga está incluso. 
Tabela 6 Setor Agropecuário na Região Metropolitana de Sorocaba.

\begin{tabular}{|c|c|c|}
\hline $\begin{array}{c}\text { Participação no Valor } \\
\text { adicionado }(2013)^{11}\end{array}$ & $\begin{array}{c}\text { No total de Estabelecimentos } \\
(2016)\end{array}$ & $\begin{array}{c}\text { No total de empregos } \\
(2016)\end{array}$ \\
\hline $2,99 \%^{12}$ & $8,56 \%$ & $4,66 \%$ \\
\hline
\end{tabular}

Fonte: Seade - Caged. Elaboração dos autores.

Por ter sido muito recente, no site do Seade, não encontramos estatísticas agregadas da Região Metropolitana de Sorocaba ${ }^{13}$. Assim seguimos a metodologia de somar o valor adicionado do setor agropecuário dos municípios que a compõe e dividir pelo valor adicionado total desses mesmos municípios, de maneira a obter a participação do setor na Região. Assim, com base em dados de 2013, temos a seguinte participação do setor na Região Metropolitana de Sorocaba conforme a Tabela 6.

Confrontando os dados Brasil, do Estado de São Paulo e da Região Metropolitana de Sorocaba temos a elucidativa Tabela 7.

Tabela 7 Setor Agropecuário Brasil-São Paulo.

\begin{tabular}{|c|c|c|l|}
\hline $\begin{array}{c}\text { No PIB } \\
(2013)\end{array}$ & $\begin{array}{c}\text { No total } \\
\text { de Estabelecimentos (2016) }\end{array}$ & $\begin{array}{c}\text { No total } \\
\text { de empregos (2016) }\end{array}$ & \multicolumn{1}{|c|}{ Origem } \\
\hline $4,46 \%$ & $6,38 \%$ & $3,92 \%$ & Brasil \\
\hline $1,87 \%{ }^{14}$ & $7,73 \%$ & $2,84 \%$ & Estado de São Paulo \\
\hline $\mathbf{2 , 9 9 \%}$ & $\mathbf{8 , 5 6 \%}$ & $\mathbf{4 , 6 6 \%}$ & Região Metr. de Sorocaba \\
\hline
\end{tabular}

Fonte: Seade - Caged - Contas Nacionais - IBGE. Elaboração dos autores.

Como é possível observar, a participação do setor agropecuário no PIB da Região Metropolitana de Sorocaba é cerca de 33\% menor em termos relativos que a participação do setor no Brasil, mas 37,5\% superior à participação no estado de São Paulo.

11 Em 2014, caiu para 2,66\%. Mesmo com essa queda continua maior do que as demais, salvo para a Região Metropolitana de Ribeirão Preto, criada em julho de 2016. Antes dessa data Sorocaba tinha a maior participação agrícola dentre todas as regiões metropolitanas.

12 Essa participação é sobre o valor adicionado, então tecnicamente os números difeririam um pouco. Adiante tudo que falarmos participação no PIB local, seja nas regiōes metropolitanas, ou nos municípios, estaremos, na verdade, medindo a participação sobre o valor adicionado, assim, lembrando que os números tecnicamente, considerando impostos, difeririam um pouco.

13 Essa realidade já mudou um pouco. O Seade, agora em 2017 já tem muitas estatísticas da Regiāo Metropolitana de Sorocaba. Quando elaboramos o documento mestre que derivamos esse artigo a realidade era outra.

14 Valor Adicionado. 
De outro lado, importante salientar que a participação do setor em termos de estabelecimentos formalizados supera a participação no Estado e no Brasil, assim como a participação na geração de empregos supera a do estado e no Brasil.

Esses números, por si só, já justificaria um olhar mais apurado para a agricultura da Região Metropolitana de Sorocaba. Nossa afirmação fica corroborada quando comparamos às demais regiōes metropolitanas do Estado de São Paulo conforme a Tabela 8 .

Tabela 8 Participação do Setor Agropecuário nas Regiões Metropolitanas de São Paulo.

\begin{tabular}{|l|c|c|}
\hline \multicolumn{1}{|c|}{ Regiões Metropolitanas } & Ano & $\begin{array}{c}\text { Participação da Agropecuária } \\
\text { no Valor Adicionado da Região } \\
\text { Metropolitana\% }\end{array}$ \\
\hline $\begin{array}{l}\text { Região Metropolitana de Ribeirão Preto } \\
\text { Região Metropolitana de Sorocaba }\end{array}$ & 2013 & $\mathbf{5 , 2 7}$ \\
\hline Região Metropolitana de Campinas & 2013 & $\mathbf{2 , 9 9}$ \\
\hline Região Metropolitana do Vale do Paraíba e & 2013 & 0,53 \\
\hline Litoral Norte & 2013 & 0,28 \\
\hline Região Metropolitana da Baixada Santista & 2013 & 0,13 \\
\hline Região Metropolitana de São Paulo & & \multicolumn{2}{|c|}{} \\
\hline
\end{tabular}

Fonte: Elaboração dos autores com base nos dados da Seade.

Para o ano de 2013, somados o valor adicionado da agricultura dos municípios que compõem a RMS e depois dividimos pelo somatório do valor adicionado total dos mesmos municípios, encontrando a participação do setor no valor adicionado total da Região, uma vez que a Região só foi criada em 2014. A mesma coisa foi feita com a Região Metropolitana de Ribeirão Preto, só criada em 2016.

Como podemos ver, a participação relativa do setor agropecuário no valor adicionado da Região Metropolitana de Sorocaba é a segunda maior de todas as participações relativas das regiōes metropolitanas do estado de São Paulo. Mais uma vez os números nos sinalizam a necessidade de um olhar diferenciado para a agropecuária na nossa Região. Se considerarmos com o histórico agropecuário do Vale do Paraíba ou mesmo de Campinas (café, pecuária etc.), a participação da RMS é, respectivamente, 464\% e 193\% maior do que essas regiōes mencionadas, embora seja 43,26\% menos do que a Região Metropolitana de Ribeirão Preto. 
-• Economia Brasileira em Debate

\subsection{Participação do setor nos empregos formais e no número de estabelecimentos da RMS}

Segundo dados do Caged a distribuição dos empregos formais na Região Metropolitana de Sorocaba está assim disposta:

Tabela 9 Participação dos setores no volume de emprego da RMS (2016).

\begin{tabular}{|l|l|l|}
\hline \multicolumn{1}{|c|}{ Setor } & \multicolumn{1}{c|}{ Empregos } & \multicolumn{1}{c|}{ Participação } \\
\hline Agropecuária & 23.670 & 4,66 \\
\hline Indústria de transformação & 167.268 & 32,92 \\
\hline Comércio & 113.267 & 22,29 \\
\hline Serviços & 167.816 & 33,03 \\
\hline Demais setores & 36.058 & 7,10 \\
\hline Total de empregos na RMS & $\mathbf{5 0 8 . 0 7 9}$ & $\mathbf{1 0 0 , 0 0}$ \\
\hline
\end{tabular}

Fonte: Elaboração dos autores, com base nos dados do Caged.

E quando olhamos a participação no número de estabelecimentos, temos:

Tabela 10 Participação dos setores no número de estabelecimentos da RMS (2016).

\begin{tabular}{|l|c|c|}
\hline \multicolumn{1}{|c|}{ Setor } & Estabelecimentos & Participação \% \\
\hline Agropecuária & 8.409 & 8,56 \\
\hline Indústria de Transformação & 8.188 & 8,34 \\
\hline Comércio & 34.487 & 35,12 \\
\hline Serviços & 42.639 & 43,43 \\
\hline Demais setores & 4.466 & 4,55 \\
\hline Total de empregos na RMS & $\mathbf{9 8 . 1 8 9}$ & $\mathbf{1 0 0 , 0 0}$ \\
\hline
\end{tabular}

Fonte: Elaboração dos autores com base nos dados do Caged.

Esses números apontam algumas perguntas sobre o emprego na Região Metropolitana de Sorocaba que precisam ser respondidas pois, como podemos ver, a participação no volume de empregos formais para é de 4,66\% e para a Indústria de Transformação é de 32,92\%. Mas quando comparados com o número de estabelecimentos temos que o setor industrial tem menos estabelecimentos que o setor agropecuário. 
Indicadores comparados da produção agrícola da região metropolitana de Sorocaba ••

Tabela 11 Potencial de Oferta de cursos de capacitação para o setor.

\begin{tabular}{|c|c|c|c|}
\hline Cursos & Nível & $\begin{array}{l}\text { Correlação } \\
\text { com o setor }\end{array}$ & $\begin{array}{l}\text { Oferta } \\
\text { na rms }\end{array}$ \\
\hline Tecnologia em agronegócios & Graduação & Direta & 1 \\
\hline Agronomia; engenharia agronômica & Superior & Direta & 2 \\
\hline Gestão de equinocultura & Graduação/tecnológico & Direta & 1 \\
\hline Engenharia de alimentos & Graduação/bacharelado & Direta & 1 \\
\hline Medicina veterinária & Graduação bacharelado & Direta & 2 \\
\hline $\begin{array}{l}\text { Engenharia de bioprocessos } \\
\text { e biotecnologia }\end{array}$ & Graduação bacharelado & Direta & 1 \\
\hline Gastronomia & Graduação/tecnológico & Direta & 2 \\
\hline Engenharia florestal & Graduação/bacharelado & Direta & 1 \\
\hline Tecnologia em viticultura e enologia & Graduação/tecnológico & Direta & 1 \\
\hline Logística & Graduação/tecnológico & Transversal & 4 \\
\hline Gestão ambiental & Tecnológico/graduação & Transversal & 3 \\
\hline Ciências biológicas & $\begin{array}{l}\text { Graduação/bacharelado/ } \\
\text { licenciatura }\end{array}$ & Transversal & 3 \\
\hline Mba em armazenagem e distribuição & Pós lato sensu & Transversal & 1 \\
\hline Engenharia ambiental & Graduação/bacharelado & Transversal & 2 \\
\hline Ciências ambientais & Pós-graduação stricto sensu & Transversal & 1 \\
\hline $\begin{array}{l}\text { Biotecnologia e monitoramento } \\
\text { ambiental }\end{array}$ & Pós-graduação stricto sensu & Transversal & 1 \\
\hline Processos tecnológicos e ambientais & $\begin{array}{l}\text { Pós-graduação stricto sensu } \\
\text { (profissional) }\end{array}$ & Transversal & 1 \\
\hline Farmácia & Pós-graduação stricto sensu & Transversal & 1 \\
\hline
\end{tabular}

Fonte: Elaboração dos autores, com base em Ribeiro, et al., 2017.

Podemos criar, com certos graus de liberdade, duas hipóteses: A Região Metropolitana de Sorocaba concentra grandes empresas, e é natural que o número de estabelecimentos se assemelhe e até perca para o número de estabelecimentos agrícolas, mas por serem grandes empresas empregam muitas pessoas. A segunda hipótese é de que a Região Metropolitana de Sorocaba tem grande produção agrícola, mas concentrada em produção familiar. Assim há um grande número de estabelecimentos, mas não necessariamente, de empregos formais. 
Qualquer defesa de ambas hipóteses sem um estudo mais detalhado será imprudente. Por que, é verdade que Sorocaba concentra grandes indústrias, inclusive os chamados "Tiers 1" para a indústria automobilística, possui uma montadora (Toyota) e suas sistemistas, uma forte tradição metal mecânica, a puxar os números para a toda Região Metropolitana.

Por outro lado, a Região Metropolitana de Sorocaba responde por $20 \%$ de toda a produção de hortaliças e legumes (Olericultura) do estado de São Paulo, e representa 22\% do Valor Bruto da Produção (Ribeiro et al., 2017 p. 19-21).

Não à toa que o Conselho Municipal de Agricultura, Pecuária e Abastecimento capitaneou a criação da Lei Municipal 11.479 que "Dispõe sobre as Diretrizes da Política Municipal Agrícola e dá outras providências”, modelo que, se bem-sucedido entre a prática legislativa e o fomento do setor, poderá ser estendido para os demais municípios da RMS, em especial para Piedade e Ibiúna, que são os celeiros Olerícolas da RMS ou mesmo abastecendo a Região Metropolitana de São Paulo.

Assim afigura-se um campo promissor para pesquisas não só sobre os empregos agrícolas na Região Metropolitana de Sorocaba, como também as possibilidades de emprego e geração de renda de atividades vinculadas ao agronegócio, em função da própria oferta de cursos de pós-graduação, graduação, tecnológicos, e técnicos ofertados na Região, que tem correlação direta ou transversal com o setor agropecuário.

A Região Metropolitana de Sorocaba ainda não sabe a sua taxa de desemprego por não ter sido ainda incluída nas pesquisas do IBGE, FIPE e demais órgão de pesquisa. Tem, seguramente, dentre as Regiões Metropolitanas do estado, a segunda maior participação agrícola. No entanto, representa apenas 4,66\% dos empregos formais, mas supera a indústria, quando comparado ao total de estabelecimentos.

Por outro lado, conforme já mencionamos, a Região Metropolitana de Sorocaba responde por $20 \%$ da produção e $22 \%$ do valor bruto da produção de toda a Olericultura produzida no estado de São Paulo.

Adicionalmente, Sorocaba sedia um Parque Tecnológico, e como vimos tem uma significativa oferta de cursos superiores que permitem formar profissionais e empreendedores do setor e Sorocaba lidera a construção de uma Política Pública Agrícola, ao menos do ponto de vista de se construir um arcabouço regulatório. Essa experiência potencializando seus acertos e evitando seus erros poderá ser expandida para toda a Região, especialmente para cidade onde a agricultura é marcante, tais como Piedade e Ibiúna. 
A Região oferece cursos superiores direta e indiretamente ligados ao setor, com profissionais pesquisadores da área em que muito podem contribuir para pesquisas.

\section{CONSIDERAÇÕES FINAIS}

Conhecer quem são e como agem os empreendedores agrícolas, como eles se posicionam frente ao emprego formal, qual a qualidade desse emprego, qual o grau de capacitação desses empreendedores e que tipo de habilidades e competências necessitam, são questôes fundamentais que se apresentam para potencializar o enorme ativo que temos: ser a segunda maior produção agrícola de das Regiōes Metropolitanas de São Paulo.

No filme A lista de Schindler, Itzhak Stern (interpretado por Ben Kingsley) diz "A lista é um bem absoluto, a lista é vida! Nas margens e em volta fica o abismo". Fazendo um paralelo, a produção agrícola na Região Metropolitana de Sorocaba, é um bem absoluto. Ela pode significar, vida, desenvolvimento. Mas, para isso, precisamos de pesquisas em economia do trabalho, entre outras, para que o abismo do desconhecimento, não desperdice tantas oportunidades.

Com um Parque Tecnológico recém-inaugurado (2012), com um campo enorme de experiências para Embrapa Hortaliças (Produção de mais de um milhão de toneladas anuais) e com Universidades e corpo de pesquisadores ávidos por desenvolver projetos de pesquisa, é necessário colocar essa roda em movimento.

Conhecer como se dá o empreendedorismo e a qualificação da mão de obra agrícola seus efeitos diretos e indiretos, será importantíssimo para que essa roda gire.

\section{REFER̂̂NCIAS}

SPIELBERG, Steve, A LISTA DE SCHINDLER. Concepção e Direção de Steven Spielberg. Los Angeles, CA: Universal Studios, 1993.

CENTRO UNIVERSITÁRIO NOSSA SENHORA DO PATROCÍNIO-CEUNSP. Graduação. Disponível em: http://www.ceunsp.edu.br/graduacao/. Acesso em: 3 mar. 2017.

FACULDADE ANHANGUERA. Graduação. Disponível em: http://anhanguera.com/ graduacao/cursos/cursos.php. Acesso em: 3 mar. 2017.

FACULDADE DE TECNOLOGIA JOSÉ CRESPO GONZALES (FATEC SOROCABA) Cursos. Disponível em: http://www.fatecsorocaba.edu.br/default.asp. Acesso em: 3 mar. 2017. 
FACULDADE DE TECNOLOGIA DE ITAPETININGA - PROFESSOR ANTONIO BELIZANDRO BARBOSA DE REZENDE. Cursos. Disponível em: https:// fatecitapetininga.edu.br/cursos/. Acesso em: 3 mar. 2017.

FACULDADE DE TECNOLOGIA DE POMPEIA SHUNJI NISHIMURA. Cursos. Disponível em: http://www.fatecpompeia.edu.br/index.php\#. Acesso em: 3 mar. 2017.

FACULDADES INTEGRADAS DE ITAPETININGA - FUNDAÇÃO KARNIG BAZARIAN-FKB. Cursos. Disponível em: http://www.fkb.br/cstlog.html\#. Acesso em: 3 mar. 2017.

FIBGE - Fundação Instituto Brasileiro de Geografia e Estatística. Censos Agropecuários de 1996 e 2006. Rio de Janeiro: FIBGE, vários anos. 'Olhares sobre o processo investigativo’ FIBGE - Fundação Instituto Brasileiro de Geografia e Estatística. Produção Agrícola Municipal de 1991 e 2006. Rio de Janeiro: FIBGE. www.ibge.gov.br.

FIBGE - Fundação Instituto Brasileiro de Geografia e Estatística. Pesquisa Nacional por Amostra de Domicílios Contínua - PNAD. Disponível em: ftp://ftp. ibge.gov.br/ Trabalho_e_Rendimento/Pesquisa_Nacional_por_Amostra_de_Domicilios_continua/ Trimestral/Comentarios_Sinteticos/pnadc_201604_trimestre_comentarios_sinteticos_ Brasil.pdf Recuperado em 20 abr. 2017.

FUNDAÇÃO SISTEMA ESTADUAL DE ANÁLISE DE DADOS. Banco de dados Disponível em: http://www.Seade.sp.gov.br FUNDAÇÃO SISTEMA ESTADUAL DE ANÁLISE DE DADOS. Perfil dos municípios paulistas. Disponível em: <http://www. Seade.sp.gov.br>.

INSTITUTO FEDERAL SÃO PAULO. Cursos. Disponível em: http://srq.ifsp.edu.br/ index.php/campus/cursos. Acesso em: 3 mar. 2017.

MINISTÉRIO DO TRABALHO. Cadastro Geral de Empregados e Desempregados. Perfil do Município. http://bi.mte.gov.br/bgcaged/caged_perfil_municipio/index.php. Acessado em 10 abr. 2017.

PEDRETTI, Luiz José et al. Processo de Criação da Região Metropolitana de Sorocaba. São Paulo: EMPLASA, 2013.

RIBEIRO, F. C. et al. Elementos da Economia Agricola e Olericultura da Regiāo Metropolitana de Sorocaba. Um celeiro produtivo e farto para Pesquisas. Sorocaba: inédito, 2017. 49p.

UNIVERSIDADE DE SOROCABA-UNISO. Graduação. Disponível em: http://www. uniso.br/graduacao/default.asp. Acesso em: 3 mar. 2017.

MBA e Especialização. Disponível em: http://latosensu.uniso.br/cursos/. Acesso em: 3 mar. 2017.

UNIVERSIDADE FEDERAL DE SÃO CARLOS-UFSCAR Graduação. Disponível em: http://www.sorocaba.ufscar.br/ufscar/index.php?mn_id=19. Acesso em: 3 mar. 2017. 
Indicadores comparados da produção agrícola da região metropolitana de Sorocaba

- Pós-graduação. Disponível em: http://www.sorocaba.ufscar.br/ufscar/index. php?mn_id=20. Acesso em: 3 mar. 2017.

UNIVERSIDADE PAULISTA - UNIP. Cursos Tradicionais. Disponível em: http:// www.unip.br/ensino/graduacao/tradicionais/index.aspx. Acesso em: 3 mar. 2017.

. Cursos Tecnológicos. http://www.unip.br/ensino/graduacao/tecnologicos/index. aspx. Acesso em 3 mar. 2017.

UNIVERSIDADE PAULISTA JULIO MESQUITA FILHO-UNESP. Graduação. Disponível em: http://www.sorocaba.unesp.br/\#!/graduacao/engenharia-ambiental/. Acesso em: 3 mar. 2017.

. Pós-graduação Stricto sensu. http://www.sorocaba.unesp.br/\#!/pos-graduacao/ stricto-sensu/. Acesso em: 3 mar. 2017. 
